\title{
Wave Transformation in a Multi-Bar Surf Zone: Case Study of Lubiatowo (Poland)
}

\author{
Yuan-Jyh Lan ${ }^{1}$, Tai-Wen Hsu ${ }^{1,2}$, Rafał Ostrowski ${ }^{3}$, \\ Marek Szmytkiewicz ${ }^{3}$ \\ ${ }^{1}$ Research Center for Ocean Energy and Strategies, National Taiwan Ocean University, 2 Pei-Ning Road, \\ Keelung, 20224, Taiwan, e-mail: yjlan@mail.ntou.edu.tw, \\ ${ }^{2}$ Department of Harbor and River Engineering, National Taiwan Ocean University, 2 Pei-Ning Road, \\ Keelung, 20224, Taiwan, e-mail: twhsu@ mail.ntou.edu.tw (corresponding author) \\ ${ }^{3}$ Institute of Hydro-Engineering, Polish Academy of Sciences, ul. Kościerska 7, 80-328 Gdańsk, Poland, \\ e-mails: rafal.o@ibwpan.gda.pl, mareksz@ibwpan.gda.pl
}

(Received March 09, 2016; revised June 05, 2016)

\begin{abstract}
The paper presents results of field and theoretical investigations of wave transformation in the surf zone near the IBW PAN Coastal Research Station in Lubiatowo (Poland, the south Baltic Sea). The study site displays multi-bar cross-shore profiles that intensively dissipate wave energy, mostly induced by breaking. The main field data comprise wave heights and cross-shore bathymetric profiles. Wave transformation is modelled theoretically by two approaches, namely the IBW PAN phase-averaged wave transformation model and the approach based on the hydraulic jump model, developed by Hsu \& Lai (2009) for hydrological situations encountered under the actual conditions of two field campaigns - in 1987 and 1996. Discrepancies between the measured data and the model results are discussed. In general, the model results are in good agreement with the in-situ observations. The comparison of the field data with the computational results concerns a part of the surf zone between about $5 \mathrm{~m}$ water depth and the first nearshore stable bar, where the depth amounts to ca. $1.2 \mathrm{~m}$.
\end{abstract}

Key words: wave transformation, wave energy dissipation, wave breaking, multi-bar cross-shore profile, phase-averaged model, hydraulic jump model.

\section{Introduction}

In coastal zones, wave transformation plays a key role in hydrodynamics. Aside from processes such as diffraction, refraction, shoaling and reflection, in which wave energy is conserved, waves are subject to energy loss. Wave transformation on a mildly inclined nearshore bottom is dominated by wave energy dissipation, mostly due to breaking. Wave breaking occurs when the wave steepness becomes very high, especially near the wave crest. In such a case, the velocities of water particles in the wave crest exceed the wave celerity, so that the wave becomes unstable and breaks with the 
crest thrown forward as the wave disintegrates into bubbles and foam. The knowledge of wave parameters conducive to wave breaking and energy decay is important in the modelling of wave-induced set-up, nearshore currents and forces on coastal structures.

Numerous experimental investigations, mostly under laboratory conditions, as well as numerical and analytical studies, have been performed to describe wave height variation across the surf zone. Most of related research focused on the energy balance equation, in which the energy dissipation rate due to boundary shear stress and turbulence is specified. Mizuguchi (1980) used an expression of energy dissipation allowing for the viscous effect and turbulence. For random waves, Battjes \& Janssen (1978) and Battjes \& Stive (1985) used the Le Méhauté (1972) formula for describing energy dissipation resulting from wave breaking. An important element of this description is the breaking coefficient. Experiments conducted by Horikawa \& Kuo (1966) showed that the key feature of wave height variation across the surf zone is the wave height stabilizing at a uniform depth for the initial wave breaking. On the basis of the experimental results of Horikawa \& Kuo, Dally et al (1985) developed a model in which wave energy dissipation was proportional to the difference between the local energy flux and the stable energy flux. This model was named the hydraulic jump model (HJM). Its advantage is that it is capable of reproducing the pause (or stop breaking) in the wave breaking process at a finite wave height on a horizontal or sloping bed or in the recovery zone (Winyu \& Shibayama, 1996). Hsu \& Lai (2009) presented a theory based on the HJM for describing wave transformation across a single-bar beach profile. The IBW PAN model of wave transformation was developed by Szmytkiewicz (2002) on the basis of the phase-averaged energy dissipation formula of Battjes \& Janssen (1978) by adding a factor describing the percentage of broken and breaking waves. In all of the above wave transformation models, wave breaking was assumed to be the predominant mechanism of wave energy dissipation.

The aim of the present study is to investigate wave transformation in the surf zone characterised by a multi-bar sea bottom profile. Both the IBW PAN model and the HJM are applied to the case of wave propagation over a multi-bar beach profile. The objective of the study is accomplished with the use of field data and two theoretical approaches. The comparison of the field data and the results yielded by the models does not concern the entire surf zone, but a part of it, stretching from about $5 \mathrm{~m}$ water depth to the first nearshore stable bar at a depth of about $1.2 \mathrm{~m}$.

\section{Site and Data}

The field data used in the present study were collected at the Coastal Research Station (CRS) in Lubiatowo, operated by the Institute of Hydro-Engineering of the Polish Academy of Sciences (IBW PAN). The bathymetric surveys and wave measurements were carried out in September 1987 and in October/November 1996.

The study area of CRS Lubiatowo is a typical south Baltic sandy coast situated about $70 \mathrm{~km} \mathrm{NW}$ of Gdańsk (Fig. 1), with the laboratory building at the coordinates 
$54^{\circ} 48^{\prime} 42.0^{\prime \prime} \mathrm{N} 17^{\circ} 50^{\prime} 25.6^{\prime \prime} \mathrm{E}$. The area is dominated by westerly and south-westerly winds, which are strongest in the autumn and winter.

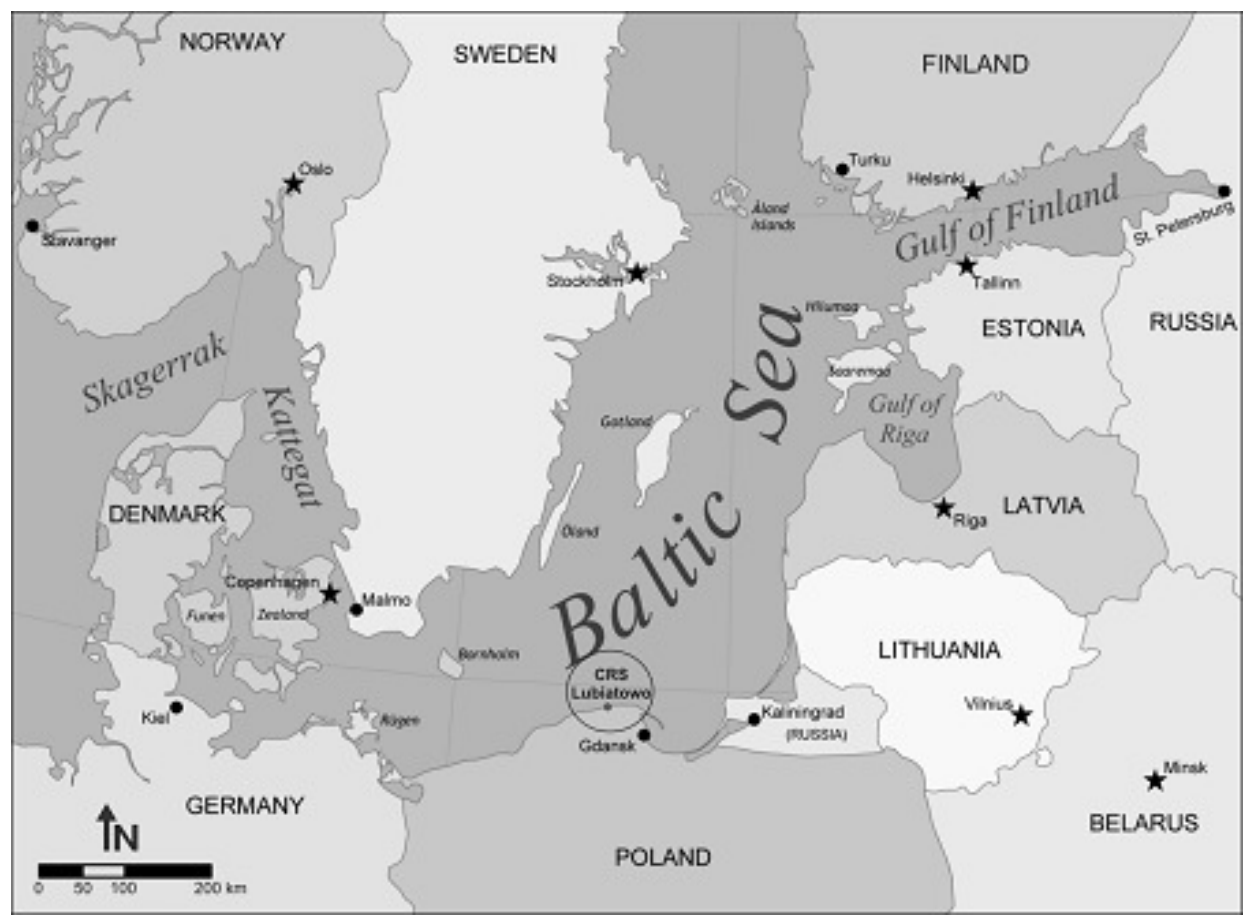

Fig. 1. Location of CRS Lubiatowo on the Baltic coast

The shore in the vicinity of CRS Lubiatowo is an open natural beach, characterised by a gentle slope (about $1.5 \%$ ), with the median sediment diameter oscillating about an average value of $d_{50}=0.22 \mathrm{~mm}$. The shore is relatively stable, although a very gentle erosive tendency has been observed over last years. The mean beach width lies between 15 and $50 \mathrm{~m}$. The beach is bounded by dunes and features multi-bar cross-shore profiles, which usually show 4 stable bars (see Fig. 2) following an ephemeral one, near the shoreline. The ephemeral bar interacts with the shoreline, supplying or removing sediment and simultaneously protecting the shore from wave action. In extreme situations of storms or long calm periods, in-situ measurements indicate that this bar seldom exists. Under stormy conditions, it is washed away as the material moves offshore, and during quiet periods, the bar moves onshore until it arrives on the shoreline. This causes the beach to rebuild and leads to berm formation.

Due to the presence of the bars, waves approaching the shore from the deep sea are subject to considerable transformation in the surf zone, and most of wave energy is dissipated because of multiple wave breaking. According to Pruszak et al (2008), if the significant wave height $H_{s}$ in deep water exceeds $1.5-2 \mathrm{~m}$, the mean wave energy dissipated on the cross-shore profile with three offshore bars (the bars II, III and IV) 


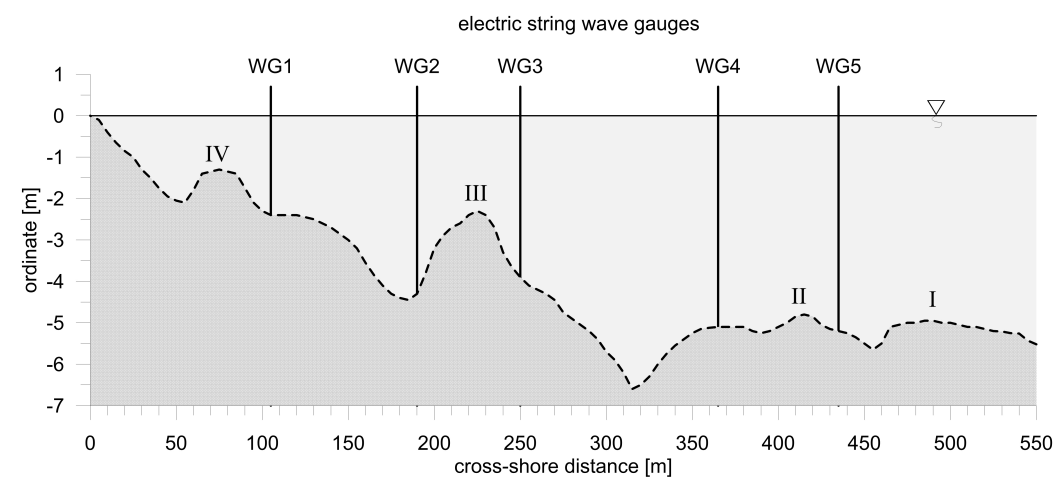

Fig. 2. Shape of the measuring profile and the location of wave gauges at CRS Lubiatowo in September 1987

a mounts to about $80 \%$ of the input deep-water wave energy. This means that in such cases no more than $20 \%$ of wave energy reaches bar I, and even less reaches the vicinity of the shoreline. For deep-water waves of smaller heights $\left(H_{s}<0.5-1.0 \mathrm{~m}\right)$, the amount of wave energy reaching the vicinity of bar I and the shoreline increases to $30-50 \%$ of the deep-water wave energy.

Taking into account the way in which wave energy transforms on the cross-shore profile, one can distinguish two basic types of the sea shore. One type are dissipative shores, at which most of wave energy dissipates due to wave breaking in the surf zone, and the other are reflective shores, at which waves are subject to reflection from the nearshore slope. The characteristics of the shore depend on the shoreface slope and the features of a representative wave. In the assessment of the shore type, a so-called surf scale parameter proposed by Komar (1998) is used, which is written in the form

$$
\varepsilon=\frac{2 \pi^{2} H_{b}}{g T^{2} \tan ^{2} \beta}
$$

where $H_{b}$ is the breaking wave height, $g$ is the acceleration due to gravity, $T$ is the wave period, and $\beta$ is the angle of the mean seabed inclination.

The higher the value of the parameter $\varepsilon$, the more dissipative the shore is. It is very difficult to determine the boundary value of $\varepsilon$, indicating the transition from the reflective shore to the dissipative shore. According to Komar (1998), this difficulty is related to the influence of the shape of the local bottom profile and wave parameters, which makes it possible for the outer surf zone to be dissipative in character while the steep beach face of the inner zone is more reflective. Furthermore, determination of the breaking wave height $H_{b}$ and the representative wave period $T$ is to a large extent arbitrary and thus problematic. Nevertheless, the assessment of the type of the shore by means of the surf scale parameter $\varepsilon$ seems feasible.

The average nearshore bottom slope at CRS Lubiatowo (about $500 \mathrm{~m}$ seawards from the shoreline) amounts to $\tan \beta=0.012$. Assuming the long-term mean height of the breaking wave for the south Baltic coast equal to about $0.3-0.6 \mathrm{~m}$ and the wave 
period of $3.5 \mathrm{~s}$, we obtain the value of $\varepsilon$ in the range of 342-684. Similar assessments for the Black Sea coast at Shkorpilovtsi (40 km south of Varna, Bulgaria) were presented by Ostrowski et al (2010). Steeper than at Lubiatowo, the nearshore sea bottom at Shkorpilovtsi (stretching about $500 \mathrm{~m}$ seawards from the shoreline) has an average inclination of $\tan \beta=0.025$. Further, owing to the bigger depth of the Black Sea, the wave climate is more severe than that in the Baltic Sea. The assumption of the long-term mean height of the breaking wave for the west Black Sea coast equal to about $0.8 \mathrm{~m}$ and the wave period of $6 \mathrm{~s}$, yields the value of the parameter $\varepsilon$ equal to 72. Comparison of this value with its counterpart determined for Lubiatowo (where $\varepsilon$ exceeds 300 ) suggests that the Baltic shore at Lubiatowo has a typically dissipative character.

In 1987, waves in the coastal zone of CRS Lubiatowo were recorded with a sampling frequency of $10 \mathrm{~Hz}$ by 5 electric string wave gauges installed on measuring piles located at distances of 100-430 m from the shoreline (see Fig. 2). In the region of a multi-bar profile where depth varies rapidly, the waves broke and recovered in the surf zone at least twice, with the final breaker occurring in the strictly nearshore region, very close to the shoreline. The width of the surf zone changed with varying meteorological conditions. During mild conditions, wave breaking took place only between WG1 and the shoreline. In such cases, all measuring points were located beyond the surf zone. During moderate conditions, waves broke between WG2 and WG3 (on 12 $2^{\text {th }}$ September 1987) or near WG3 (on $13^{\text {th }}$ and $15^{\text {th }}$ September 1987). In such situations, wave gauges WG1 and WG2 registered broken waves. Wave gauge WG3 recorded unbroken waves on $12^{\text {th }}$ September 1987 and breaking waves on the following days of the survey (on $13^{\text {th }}$ and $15^{\text {th }}$ September). Wave gauges WG4 and WG5 (located beyond the surf zone) registered unbroken waves under all conditions considered here.

During the measurements carried out at CRS Lubiatowo in autumn 1996, fewer electric string wave gauges were installed (3 gauges in October and 2 gauges in November), but the parameters of the incident deep-water waves were recorded by a directional wave buoy (Directional Waverider Mk. II, produced by Datawell BV, the Netherlands) moored at a depth of $20 \mathrm{~m}$, about $4.5 \mathrm{~km}$ from the shoreline (see Fig. 3). Under all conditions of this field survey, the offshore root-mean-square wave height exceeded $1.4 \mathrm{~m}$. Owing to the bathymetric layout in autumn 1996, such high waves broke and recovered at least 3 times, and the first breaker was located offshore from the position of the most seaward electric string wave gauge. Thus, all the electric string wave gauges were located within the surf zone under all conditions considered here and measured broken or breaking waves.

Both in 1987 and in 1996, wave measurements were not carried out in the shallow-water nearshore zone, at depths smaller than $1 \mathrm{~m}$. Later field surveys, conducted in the period from 2002 to 2016, comprised wave measurements at water depths amounting to $0.6-0.8 \mathrm{~m}$ (at distances of 20-60 $\mathrm{m}$ from the shoreline). Dur- 
ing these campaigns, however, few wave data were collected further from the shore, except for deep-water wave parameters (recorded by the wave buoy).

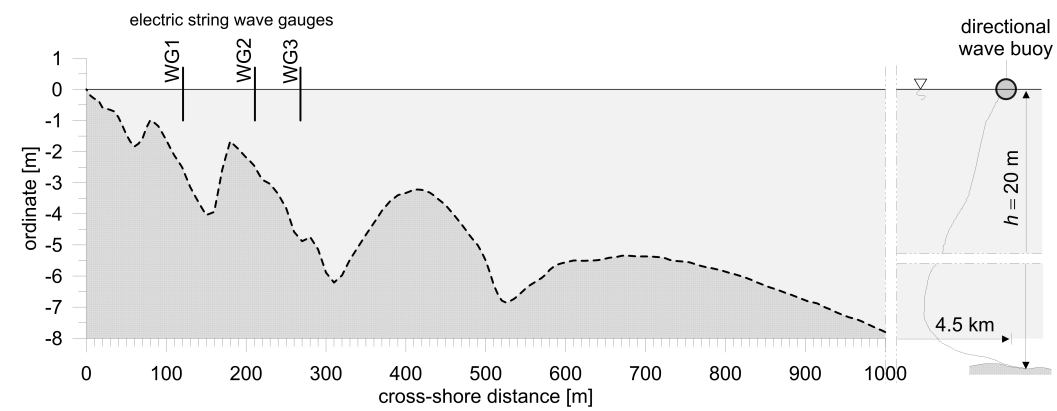

Fig. 3. Shape of the measuring profile and the location of wave gauges at CRS Lubiatowo in October/November 1996

The present study makes use of three sets of wave parameters for 1987 (Nos. $1-3)$ : those of $12^{\text {th }}, 13^{\text {th }}$ and $15^{\text {th }}$ September, as well as three sets of wave parameters for 1996 (Nos. 4-6): those of $30^{\text {th }}$ October, $6^{\text {th }}$ November and $8^{\text {th }}$ November. The parameters of incident waves are the root-mean-square wave height $H_{r m s}$, the wave peak period $T_{p}$ and the wave angle (with respect to the cross-shore transect) $\theta$. The data measured at the most seaward wave gauge (WG5) in 1987 and by the deep-water wave buoy in 1996 are given in Tables 1 and 2, respectively.

Table 1. Parameters of incident waves $(h=5.2 \mathrm{~m})$ at CRS Lubiatowo in September 1987

\begin{tabular}{|c|c|c|c|}
\hline No. of survey & $H_{r m s}[\mathrm{~m}]$ & $T_{p}[\mathrm{~s}]$ & $\theta\left[^{\circ}\right]$ \\
\hline 1 & 0.80 & 6.0 & 25 \\
\hline 2 & 1.17 & 6.1 & 20 \\
\hline 3 & 1.20 & 6.3 & 25 \\
\hline
\end{tabular}

Table 2. Parameters of incident waves $(h=20 \mathrm{~m})$ at CRS Lubiatowo in October/November 1996

\begin{tabular}{|c|c|c|c|}
\hline No. of survey & $H_{r m s}[\mathrm{~m}]$ & $T_{p}[\mathrm{~s}]$ & $\theta\left[^{\circ}\right]$ \\
\hline 4 & 1.85 & 5.7 & 36.6 \\
\hline 5 & 1.58 & 5.4 & 22.5 \\
\hline 6 & 1.41 & 5.4 & 29.5 \\
\hline
\end{tabular}

\section{Theoretical Models}

Aside from in situ investigations, the numerical modelling of the wave transformation process was carried out. To this end, two theoretical models were used: the phase-averaged model developed at IBW PAN (Gdańsk, Poland) and the model based 
on the HJM developed by Hsu \& Lai (2009). The results obtained by both models were compared with the field data.

\subsection{IBW PAN Phase-Averaged Model}

The wave transformation model developed by Szmytkiewicz (2002) and Ostrowski \& Szmytkiewicz (2004) at IBW PAN is based on the phase-averaged approach. Under the assumption of mutually parallel isobaths, the model is capable of determining wave parameters along a multi-bar beach profile. The wave transformation process with multiple wave breaking can be modelled for an arbitrary angle of deep-water waves. In the computations, following Battjes \& Janssen (1978), it is assumed that the waves are random and that their heights in the entire coastal zone can be described by a Rayleigh distribution. On the basis of experimental observations and other available data, it may be deduced that this rough assumption can lead to inaccuracies of no more than $10 \%$ in the determination of wave heights in the nearshore zone. The so-called 'roller effect' is also considered. This means that the wave breaking phenomenon is accompanied by the appearance of a rotating mass of water on the crest of the breaking wave (see Fig. 4). According to this concept, the wave energy lost during wave breaking induces the roller.
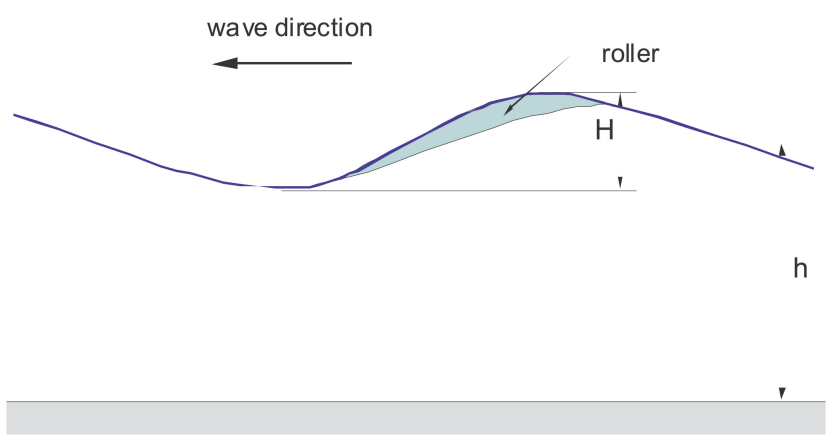

Fig. 4. Concept of a roller generated by the breaking wave

In the computational framework for wave transformation, assuming linear wave refraction, the variability of the wave approach angle is calculated from Snell's law and the wave number $k$ is determined from the dispersion relationship for the linear wave theory. Under the assumption that there are no wave reflections from the shore, the wave height $H$ is computed from the equation of the energy flux conservation:

$$
\frac{\partial}{\partial x}\left(E C_{g} \cos \theta\right)+\frac{\partial}{\partial x}\left(E_{r} C \cos \theta\right)=-D,
$$

where $E$ is the total wave energy, $E_{r}$ is the kinetic energy of the roller (as described by Svendsen 1984), $C$ and $C_{g}$ are the phase and group velocity of waves, respectively, $\theta$ is the wave approach angle, and $D$ is wave energy dissipation. 
In the above equation, which is a simplified form of the wave action equation, the wave energy dissipation $D$ is calculated on the hypothesis that the dissipation is related to the wave breaking process only. Assuming a narrow spectrum of random waves in the coastal zone and a Rayleigh distribution of the wave height, the energy dissipation of breaking waves is described by the formula of Battjes \& Janssen (1978):

$$
D=\frac{\alpha}{4} p_{b} f_{p} \rho g H_{\max }^{2},
$$

where $g$ denotes the acceleration due to gravity, $\rho$ is water density, $\alpha$ is an empirical coefficient of the order $\mathrm{O}(1), f_{p}$ is the wave spectrum peak frequency $\left(f_{p}=1 / T_{p}\right)$, while the factor $p_{b}$, describing the percentage of broken and breaking waves at a given point in the surf zone, is described by the relationship:

$$
\frac{1-p_{b}}{\ln p_{b}}=-\left(\frac{H_{r m s}}{H_{\max }}\right)^{2},
$$

in which $H_{\max }$ denotes the maximum possible wave height at a given location of the coastal zone, and $H_{r m s}$ is the root-mean-square wave height.

The wave height $H_{r m s}$ is obtained from the system of Eqs. (2), (3) and (4). The maximum possible wave height $H_{\max }$ at a given water depth $h$ in the coastal zone is defined by a criterion formulated by Miche:

$$
H_{\max }=0.88 k_{p}^{-1} \tanh \left(\frac{\gamma_{b} k_{p} h}{0.88}\right),
$$

where $k_{p}$ is the wave number calculated from the dispersion relationship for the linear wave theory with the wave spectral peak $f_{p}$, and $\gamma_{b}$ is an empirical coefficient of wave breaking.

The approach of Battjes \& Janssen (1978) has been successfully adapted to a multi-bar coastal zone and multiple wave breaking (e.g. Szmytkiewicz 2002).

In the computations, the wave set-up phenomenon is taken into account. The bottom friction, constituting another form of wave energy dissipation, is assumed to be negligibly small, which is in good agreement with some experimental assessments considered by Szmytkiewicz (2002).

\subsection{Hydraulic Jump Model}

The present model, based on the hydraulic jump model reported by Dally et al (1985) and herein referred to as the hydraulic jump model (JHM), is a modification and extension of Hsu \& Lai's (2009) theory, in which wave energy dissipation $D$ is proportional to the difference between the local energy flux and the stable energy flux, such that:

$$
D=\frac{\kappa}{h}\left[\left(E C_{g}\right)-\left(E C_{g}\right)_{s}\right]
$$


where $\kappa$ is the energy loss coefficient, while $\left(E C_{g}\right)$ and $\left(E C_{g}\right)_{s}$ denote the local energy flux and the energy flux associated with stable waves after wave breaking, respectively.

In the case of a natural beach, when storm waves approach the shore, the eroded beach presumably moves to form one or more bars offshore. This type of beach profile associated with storm waves is known as a bar beach profile. Once the offshore bar is fully formed, it causes the majority of incoming waves to break. Hsu \& Lai (2009) presented a theoretical formulation for wave height decay due to shoaling and breaking on a bar type beach profile based on the wave energy flux conservation in which the stable wave height is specified as:

$$
H_{s}=\Gamma h,
$$

where $\Gamma$ is an empirical coefficient.

Substitution of $E=\rho g H^{2} / 8$ and $C_{g}=\left(C_{g}\right)_{s}=(g h)^{0.5}$ (valid for very shallow water) in Eq. (2), with the assumption of $\cos \theta=1$ (waves approaching the shore perpendicularly) and neglecting the second term (the roller effect) on the left-hand side, yields the following expression:

$$
\frac{d G}{d x}=-\frac{\kappa}{h}\left[G-\left(\Gamma^{2} h^{\frac{5}{2}}\right)\right],
$$

where $G=H^{2} h^{0.5}$.

Then the general solution of Eq. (8) gives:

$$
G\left\{\exp \left[\int_{0}^{x} \frac{\kappa}{h} d x\right]\right\}=\int_{0}^{x} \kappa \Gamma^{2} h^{\frac{3}{2}}\left\{\exp \left[\int_{0}^{x} \frac{\kappa}{h} d x\right]\right\} d x .
$$

The solution obtained by Hsu \& Lai (2009) for the case of the single-bar bottom configuration was approximated by a fifth polynomial function.

The approach of Hsu \& Lai (2009) offers a theory for describing wave breaking and subsequent decay over a single-bar beach profile. In a natural beach profile with multi-bars in the south Baltic Sea, recovery waves may re-form in the surf zone and generate another breaking over the next bar.

In the present model, the wave energy flux conservation equation is written in the form:

$$
\frac{\partial\left(E C_{g} \cos \theta\right)}{\partial x}+\frac{\partial\left(E_{r} C \cos \theta\right)}{\partial x}=\left\{\begin{array}{cl}
-D & \text { if } D>0 \\
0 & \text { otherwise }
\end{array},\right.
$$

where $C_{g}=n C, n=[1+(2 k h / \sin 2 k h)] / 2$, and $k$ is the wave number.

According to Svensen (1984), the kinetic energy of the roller $E_{r}$ can be determined from the following equation:

$$
E_{r} C=\vartheta_{r} E C_{g}=\left(0.9 \frac{C}{C_{g}} \frac{h}{L}\right) E C_{g}=\left(0.9 \frac{1}{n} \frac{h}{L}\right) E C_{g}=\left(0.9 \frac{1}{n} \frac{k h}{2 \pi}\right) E C_{g},
$$


in which $\vartheta_{r}$ is a coefficient representing wave energy flux induced by the roller.

With the help of Eq. (11), Eq. (10) is further expressed as follows:

$$
\frac{d}{d x}\left[\left(1+\vartheta_{r}\right) E C_{g} \cos \theta\right]=\left\{\begin{array}{cl}
-D & \text { if } D>0 \\
0 & \text { otherwise }
\end{array} .\right.
$$

The angle of the approaching wave and the wave number are calculated by the dispersion relation and Snell's law based on EEMSE (evolution equation of mild slope equation) of Hsu \& Wen (2001).

The finite difference method is used to discretize Eq. (12). The finite difference equation is written as:

$$
\begin{aligned}
& \frac{d}{d x}\left[\left(1+\vartheta_{r}\right) G^{*}\right]=\frac{d \widetilde{G}}{d x}=\frac{1}{\Delta x}\left(\widetilde{G}_{i}-\widetilde{G}_{i-1}\right)= \\
= & \operatorname{Min}\left\{-\frac{\kappa}{h_{i-1}}\left[\frac{\widetilde{G}_{i-1}^{\#}}{\left(1+\vartheta_{r}\right)_{i-1}}-\Gamma^{2} h_{i-1}^{2}\left(C_{g}\right)_{i-1}\right], 0\right\}
\end{aligned}
$$

and the expression of $\widetilde{G}_{i}$ is given by:

$$
\widetilde{G}_{i}=\widetilde{G}_{i-1}+\Delta x \cdot \operatorname{Min}\left\{-\frac{\kappa}{h_{i-1}}\left[\frac{\widetilde{G}_{i-1}^{\#}}{\left(1+\vartheta_{r}\right)_{i-1}}-\Gamma^{2} h_{i-1}^{2}\left(C_{g}\right)_{i-1}\right], 0\right\},
$$

where $\widetilde{G}=\left(1+\vartheta_{r}\right) G^{*}=\left(1+\vartheta_{r}\right) H^{2} C_{g} \cos \theta, \widetilde{G}^{\#}=\left(1+\vartheta_{r}\right) H^{\# 2} C_{g}, H^{\#}$ is the representative wave height for the total energy of waves breaking in the surf zone. Min \{\} is an operator of minimum.

It should be noted that Eq. (14) can account for the wave breaking and recovery process over a multi-bar profile under the assumption of mutually parallel isobaths. In computations for irregular waves, it is assumed that the waves are random with a Rayleigh distribution (as used in the IBW PAN phase-averaged model).

\section{Results and Discussion}

Six sets of the input data: Nos. $1-3$ (of $12^{\text {th }}, 13^{\text {th }}$ and $15^{\text {th }}$ September, 1987) and Nos. 4-6 (of $30^{\text {th }}$ October, $6^{\text {th }}$ November and $8^{\text {th }}$ November, 1996), were used for numerical simulations. The parameters of incident waves, including the root-mean-square wave height $H_{0} r m s$, the wave peak period $T_{p}$ and the wave angle $\theta_{0}$, which were measured at the most seaward locations by an electric string wave gauge (WG5) in 1987 and by a deep-water wave buoy in 1996, are listed in Tables 1 and 2, respectively (see Section 2).

The data measured at CRS Lubiatowo and the theoretical results obtained by the HJM and the IBW PAN phase-averaged model are illustrated in Figs. 5-10. Because the HJM is suitable for the surf zone only, the computational region for this model was specified as the area from the first breaking point to the shoreline. The results of 
the IBW PAN model cover a slightly bigger area. It also takes the wave set-up into account. This is visible in a non-zero wave height at the shoreline.

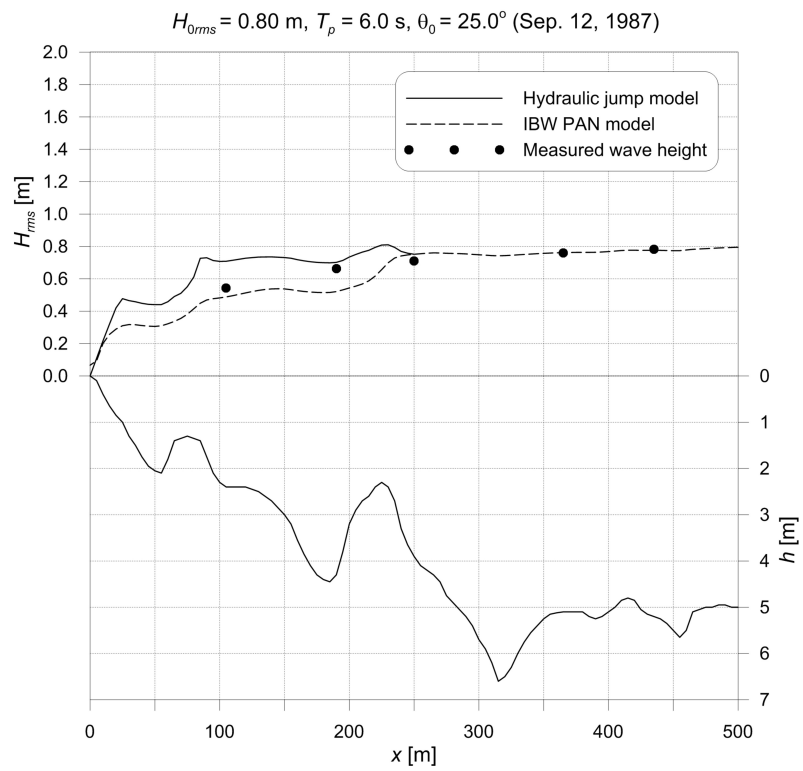

Fig. 5. Wave height modelled by two models and measured along the multi-bar cross-shore profile at CRS Lubiatowo on $12^{\text {th }}$ September 1987 (survey No. 1 in Tab. 1)

The model results presented in Figs. 5-10 show reasonably good agreement with in-situ measurements. In the first case (Fig. 5), the HJM predicts higher waves than the IBW PAN model in the entire surf zone, from a depth of about $4 \mathrm{~m}$ to the shoreline, for which the measured data lie between the lines of the model results. This indicates that the HJM overestimates the heights of breaking and broken waves, whereas the IBW PAN model underestimates them. In the remaining cases (Figs. 6-10), the HJM predicts higher waves than the IBW PAN model in the outer part of the surf zone, i.e. from depths of 4-5 $\mathrm{m}$ to depths of 1.5-2 $\mathrm{m}$. The situation is the opposite in the inner (nearshore) part of the surf zone, from depths of about 1.5-2 $\mathrm{m}$ to the shoreline. In survey No. 2 and survey No. 3 (1987), as well as in survey No. 5 (1996), the results obtained by the IBW PAN model are closer to the field data than the results of the HJM. In surveys No. 4 and 5 (1996), the accuracy of the two models seems to be different at various locations.

The mean square errors (MSE) of the results yielded by both models with respect to the field data are listed in Table 3.

The MSE values for the HJM range from 0.0064 to 0.0292 , while the MSE values for the IBW PAN model lie in the range from 0.0002 to 0.0115 . This would imply that the IBW PAN model is generally more accurate for the field experiments considered. Bearing in mind, however, issues related to structural design in the surf zone, 


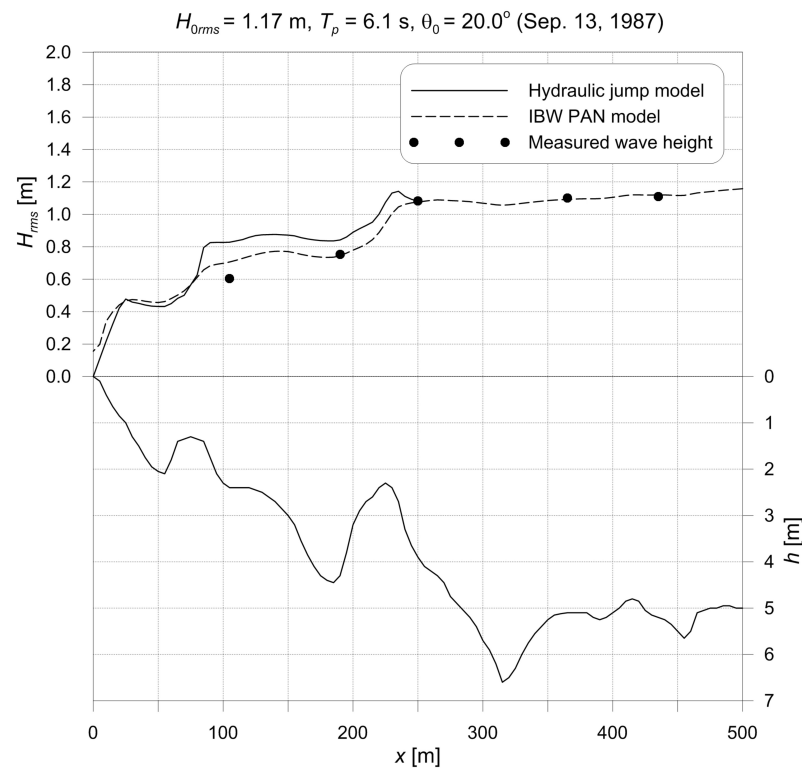

Fig. 6. Wave height modelled by two models and measured along the multi-bar cross-shore profile at CRS Lubiatowo on $13^{\text {th }}$ September 1987 (survey No. 2 in Tab. 1)

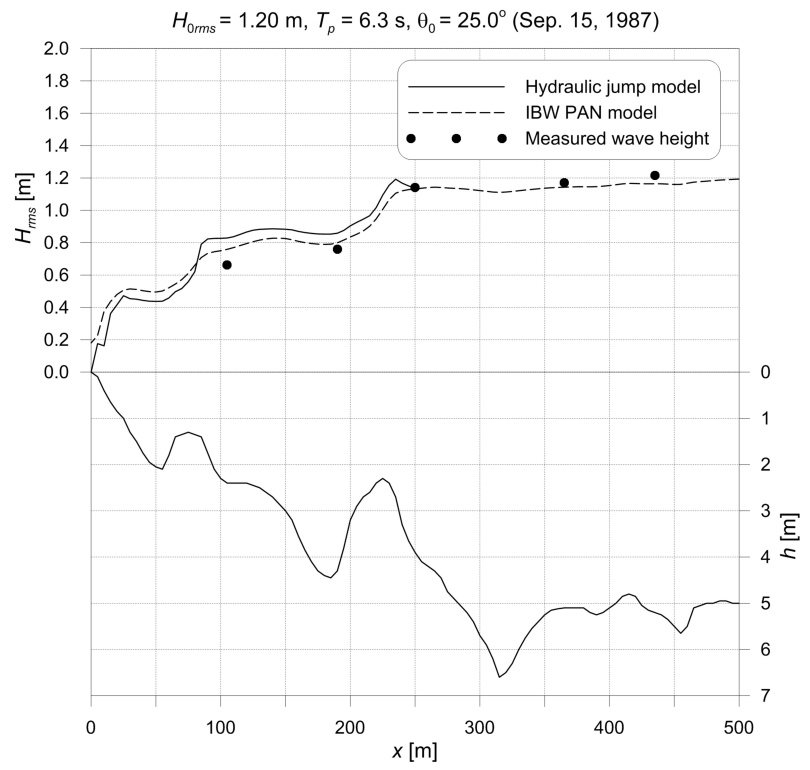

Fig. 7. Wave height modelled by two models and measured along the multi-bar cross-shore profile at CRS Lubiatowo on $15^{\text {th }}$ September 1987 (survey No. 3 in Tab. 1) 


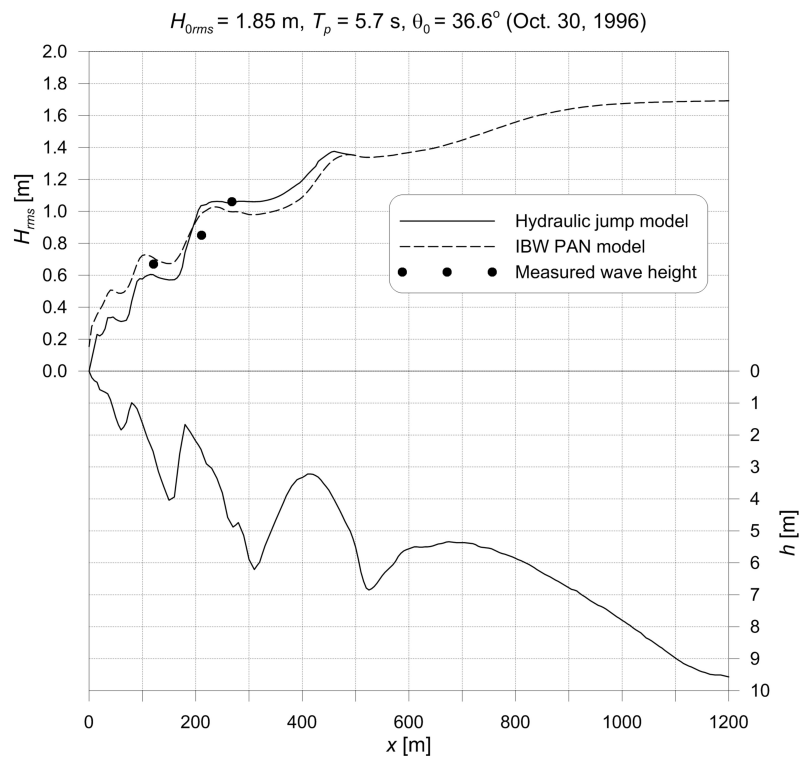

Fig. 8. Wave height modelled by two models and measured along the multi-bar cross-shore profile at CRS Lubiatowo on $30^{\text {th }}$ October 1996 (survey No. 4 in Tab. 2)

Table 3. Mean square errors (MSE) of the model with respect to the measured data

\begin{tabular}{|l|l|l|l|}
\hline 1 & $12 / 09 / 1987$ & 0.0115 & 0.0146 \\
\hline 2 & $13 / 09 / 1987$ & 0.0053 & 0.0292 \\
\hline 3 & $15 / 09 / 1987$ & 0.0055 & 0.0189 \\
\hline 4 & $30 / 10 / 1996$ & 0.0080 & 0.0131 \\
\hline 5 & $06 / 11 / 1996$ & 0.0002 & 0.0064 \\
\hline 6 & $08 / 11 / 1996$ & 0.0093 & 0.0156 \\
\hline
\end{tabular}

one should consider predictions of wave transformation models in a wider context. In particular, underestimated results deserve special attention. Wave loads on coastal structures depend on wave heights raised to a power. Therefore, even a minor underestimation of wave heights can lead to improper design of a structure, and consequently to its damage or destruction. Some data in Figs. 5, 8 and 10 suggest that the IBW PAN model underestimates the wave height, whereas the HJM overestimates it or yields correct results. For other data, the situation is the opposite, or both models underestimate the wave height. There are few cases in which both models overestimate the wave height (see Figs. 6, 7 and 9).

\section{Final Remarks and Conclusions}

The present study shows that the wave transformation process at CRS Lubiatowo is dominated by multiple wave breaking. The study site is characterised by a multi-bar sea bottom in the nearshore zone. Such a seabed relief is a bottom configuration typi- 


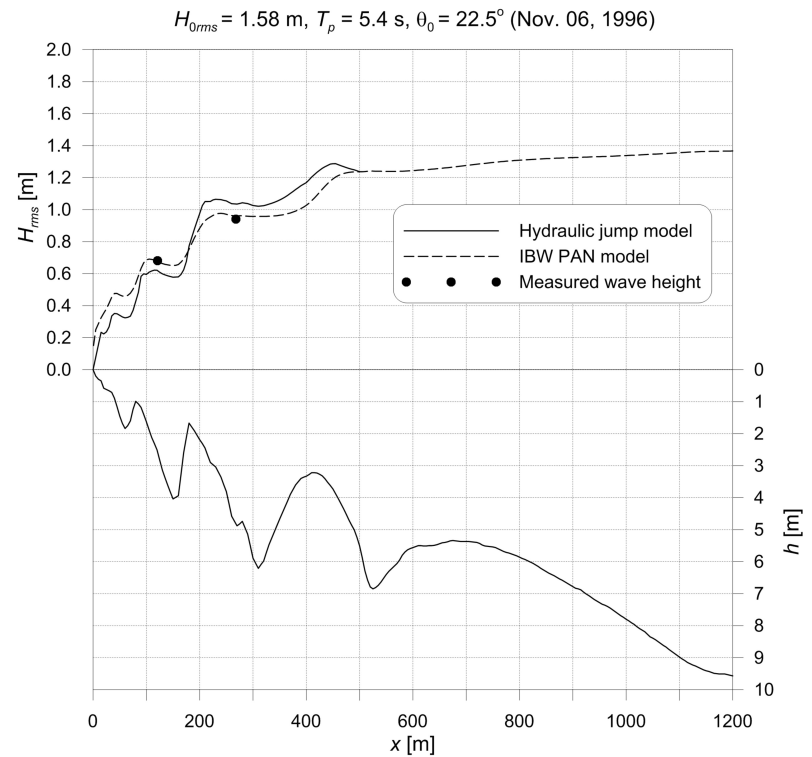

Fig. 9. Wave height modelled by two models and measured along the multi-bar cross-shore profile at CRS Lubiatowo on $6^{\text {th }}$ November 1996 (survey No. 5 in Tab. 2)

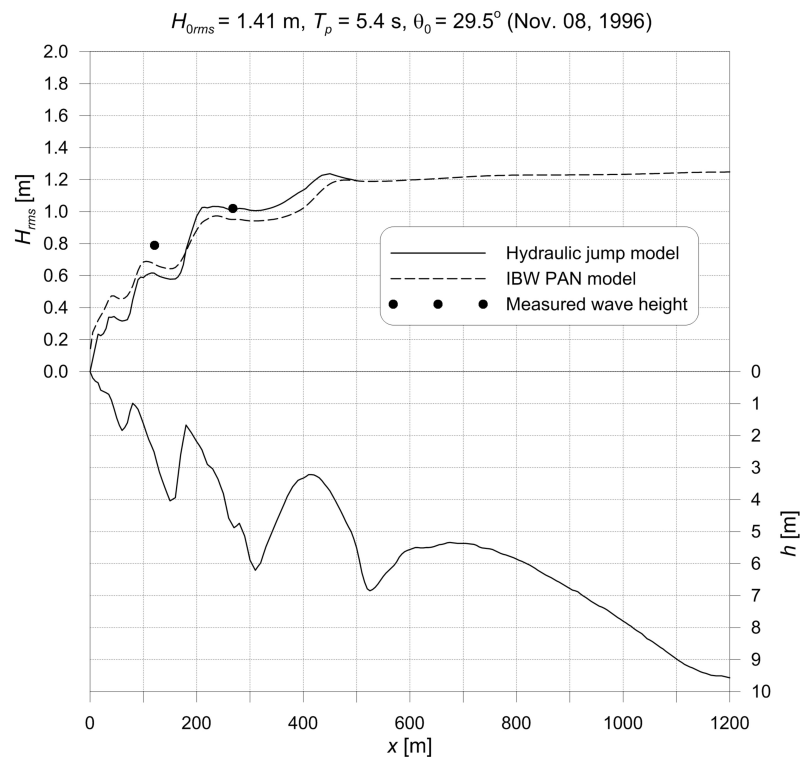

Fig. 10. Wave height modelled by two models and measured along the multi-bar cross-shore profile at CRS Lubiatowo on $8^{\text {th }}$ November 1996 (survey No. 6 in Tab. 2) 
cal of the south Baltic sandy coast. Here, except for cliff shores and intensively eroded sandy shore segments, the shape of the coastal seabed creates favourable conditions for gradual wave energy dissipation due to breaking over consecutive bars, from the offshore region to the shoreline.

The above complex process was observed during wave measurements in two field surveys and reproduced theoretically with a satisfactory accuracy by two models, namely the IBW PAN phase-averaged wave transformation model and the approach based on the hydraulic jump model, developed at the National Taiwan Ocean University.

From the engineering point of view, underestimation of wave heights by theoretical models is highly undesirable. For instance, the design weight of an individual armour unit in a rubble-mound structure is proportional to the design wave height raised to the third power (see Shore Protection Manual 1984). Therefore, even small errors in the determination of the design wave height result in considerable errors in the determination of the armour block weight. Hence, one has to be very cautious in determining design wave parameters in the surf zone. Application of more than one wave transformation model in such cases is highly recommended. Otherwise, improper structural design may occur.

The wave measurements used in this study were carried out in the surf zone at water depths bigger than ca. $1.2 \mathrm{~m}$. Later field surveys, conducted in the period from 2002 to 2016, comprised wave measurements at water depths amounting to 0.6-0.8 $\mathrm{m}$ (at distances of 20-60 $\mathrm{m}$ from the shoreline). Significantly transformed waves were observed in this specific region, where intensive sediment transport occurs. Further investigations, based on wave measurements, will be aimed at the theoretical analysis of this shallow-water nearshore zone.

\section{Acknowledgements}

The study was financially supported by the Ministry of Science and Technology (Taiwan) and the Polish Academy of Sciences as part of the Project-based Personnel Exchange Programme (PPP). On the Taiwanese side, the research was sponsored under grants NSC103-2911-I-019-505 and NSC104-2911-I-019-502. On the Polish side, it was sponsored by the Ministry of Science and Higher Education under mission-related programme No. 2 of IBW PAN. The authors wish to thank the reviewers for their helpful comments on an earlier version of this manuscript.

\section{References}

Battjes J. A., Janssen J. P. F. M. (1978) Energy loss and set-up due to breaking of random waves, Proc. $16^{\text {th }}$ International Conference on Coastal Engineering, ASCE, New York, Vol. I, 569-587.

Battjes J. A., Stive M. J. F. (1985) Calibration and verification of a dissipation model for random breaking waves, Journal of Geophysical Research, 90 (C5), 9159-9167.

Dally W. R., Dean R. G., Dalrymple R. A. (1985) Wave height variation across beaches of arbitrary profile, Journal of Geophysical Research, 90 (C6), 11917-11927. 
Horikawa K., Kuo C. T. (1966) A study on wave transformation inside the surf zone, Proceedings of 10th International Conference on Coastal Engineering, ASCE, Tokyo, 217-233.

Hsu T. W., Lai K. S. (2009) Wave height variation across surf zone on bar type profile, Proceedings of the ASME 2009 28th International Conference on Ocean, Offshore and Arctic Engineering (OMAE2009), Honolulu, Hawaii, USA, OMAE2009-80233, 1-5.

Hsu T. W., Wen C. C. (2001) On radiation boundary conditions and wave transformation across the surf zone, China Ocean Engineering, 15 (3), 395-406.

Komar P. D. (1998) Beach Processes and Sedimentation, $2^{\text {nd }}$ Edition, Prentice Hall, Upper Saddle River, New Jersey 07458, 544 pp.

Le Méhauté B. (1972) Progressive wave absorber, J. Hydraul. Res., 10 (2), $153-69$.

Mizuguchi M. (1980) An heuristic model of wave height distribution in surf zone, Proceedings of 17th International Conference on Coastal Engineering, ASCE, Sydney, Australia, 278-289.

Ostrowski R., Pruszak Z., Skaja M., Szmytkiewicz M., Trifonova E., Keremedchiev S., Andreeva N. (2010) Hydrodynamics and lithodynamics of dissipative and reflective shores in view of field investigations, Archives of Hydro-Engineering \& Environmental Mechanics, IBW PAN, Gdańsk, ]bf 57 (3-4), 219-241.

Ostrowski R., Szmytkiewicz M. (2004) Cross-shore hydrodynamics in terms of a quasi phase-resolving model, Proc. XXIV International School of Hydraulics: Hydraulic Problems in Environmental Engineering, IBW PAN, Gdańsk, 137-144.

Pruszak Z., Szmytkiewicz P., Ostrowski R., Skaja M., Szmytkiewicz M. (2008) Shallow-water wave energy dissipation in a multi-bar coastal zone, Oceanologia, 50 (1), 43-58.

Shore Protection Manual (1984) US Army Coastal Eng. Research Center.

Svendsen I. A. (1984) Mass flux and undertow in a surf zone, Coastal Engineering, Elsevier Science B.V., 8, 347-365.

Szmytkiewicz M. (2002) Quasi 3D model of wave-induced currents in coastal zone, Archives of Hydro-Engineering and Environmental Mechanics, IBW PAN, Gdańsk, 49 (1), 57-81.

Winyu R., Shibayama T. (1996) Cross-shore sediment transport and beach deformation model, Proceedings of 25th International Conference on Coastal Engineering, ASCE, Orlando, Florida, 3062-3075. 